\title{
TELAAH EKOLOGI KOMUNITAS LAMUN (SEAGRASS) PERAIRAN PULAU OSI TELUK KOTANIA KABUPATEN SERAM BAGIAN BARAT
}

\author{
Husain Latuconsina*, La Dawar** \\ *Staf Pengajar Faperta UNIDAR-Ambon, e-mail: husainlatuconsina@ymail.com \\ **Alumni Fakultas Perikanan dan Ilmu Kelautan Universitas Darussalam Ambon
}

\begin{abstract}
Abstrak
Lamun (seagrass) merupakan satu-satunya tumbuhan berbunga (angiospermae) yang mampu hidup dan berkembang dengan baik dalam keadaan tergenang air laut dan dapat tumbuh subur pada daerah pasang surut di perairan pantai dengan subtrat berupa lumpur, pasir, kerikil dan patahan karang. Penelitian ini bertujuan untuk mengetahui komposisi jenis dan struktur komunitas vegetasi lamun pada karaktersitik fisik habitat yang berbeda di perairan Pulau Osi, Teluk Kotania Kabupaten Seram Bagian Barat. Pengamatan kerapatan dan struktur komunitas lamun menggunakan metode sistematik sampling dengan bantuan transek dan kuadran yang diletakkan tegak lurus garis pantai. Hasil penelitian menemukan 4 jenis lamun yang tersebar cukup merata pada 3 stasiun pengamatan yaitu : Enhalus acoroides, Halophila ovalis, Thalasia hemprichii, dan Cymodocea rotundata, dengan komposisi dan kerapatan jenis tertinggi adalah Thalasia hemprichii dan terendah adalah Halophila ovalis. Namun demikian terdapat komposisi dan kerapatan jenis yang cukup berbeda pada masing-masing jenis lamun di setiap stasiun pengmatan, diduga berkaitan dengan karaktersitik substrat dasar perairan. Sementara nilai struktur komunitas lamun meliputi indeks dominansi masuk kategori rendah, keanekaragaman masuk kategori sedang, dam indeks keseragaman masuk kategori stabil. Hasil ini menunjukan bahwa secara ekologi tidak terdapat spesies yang sangat mendominasi dalam struktur komunitas lamun di perairan pulau Osi.
\end{abstract}

\section{Kata Kunci: Lamun, Komposisi dan Kerapatan Jenis, Struktur Komunitas, Pulau Osi}

\section{PENDAHULUAN}

Lamun (seagrass) atau disebut juga ilalang laut merupakan satu-satunya kelompok tumbuhan laut berbunga yang sudah sepenuhnya beradaptasi dengan lingkungan laut, sehingga dapat tumbuh dengan membentuk padang yang luas dan dikenal sebagai padang lamun, dan tersebar luas di perairan laut dangkal (Kordi, 2011).

Vegetasi lamun lamun hidup pada berbagai macam tipe substrat, mulai dari pecahan karang sampai sedimen dasar yang terdiri dari endapan lumpur halus. Kebutuhan substrat yang utama bagi pengembangan padang lamun adalah kedalaman sedimen. Peranan kedalaman substrat dalam stabilitas sedimen mencakup pelindung tanaman dari arus laut dan tempat pengolahan dan pemasok nutrient (Dahuri, 2003).
Menurut Nyibakken (1992), pada umumnya komunitas lamun mampu tumbuh pada semua tipe substrat, yaitu mulai dari lumpur lunak sampai batu granit, namun demikian lamun paling banyak menempati dasar perairan yang bersubstrat lunak.

Perairan pulau Osi Teluk Kotania Kabupaten Seram Bagian Barat merupakan salah satu perairan dengan potensi keragaman vegetasi lamun yang cukup tinggi dengan membentuk padang yang luas. Hasil penelitian Carppenberg (1996), menemukan 5 jenis vegetasi lamun pada perairan pulau Osi dan sekitarnya, yaitu : Enhalus acoroides, Cymodocea rotundata, Thalassia hemprichii, Halodule uninervis, dan Halophila ovalis.

Seiring dengan perubahan waktu, dan semakin bertambanya jumlah penduduk yang 
disertai dengan tingginya berbagai aktivitas masyarakat pada perairan pulau Osi seperti pembangunan pemukiman, kegiatan penangkapan, budidaya laut, transportasi laut dan sebagainya dikhawatirkan semakin memberikan tekanan ekologi bagi ekosistem padang lamun yang berada pada perairan Pulau Osi tersebut, selain itu belum adanya informasi terbaru terkait dengan komposisi dan kerapatan jenis serta struktur komunitas vegetasi lamun keterkaitannya dengan karaktersitik fisik habitatnya menjadi alasan mendasar untuk dilakukannya penelitian ini.

\subsection{Tujuan dan Manfaat Penelitian}

Penelitian ini bertujuan untuk mengetahui keterkaitan antara tingginya komposisi dan kerapatan jenis vegetasi lamun pada habitat yang berbeda karakteristik fisiknya. Sedangkan manfaat dari penelitian ini diharapkan menjadi rujukan penting terkait dengan upaya pengelolaan dan konservasi ekosistem padang lamun sebagai habitat potensial bagi sumberdaya perikanan di kawasan perairan laut dangkal.

\section{METODE PENELITIAN}

\subsection{Waktu dan Lokasi Penelitian}

Penelitian dilaksanakan dari bulan Mei Juni 2012 di perairan Pantai Pulau Osi Teluk Kotania, Kabupaten Seram Bagian Barat (Gambar 1) dengan penentuan lokasi penelitian secara purposive berdasarkan penelitian sebelumnya (Carpenberg, 1996), dan berdasarkan karakteristik fisik habitat lamun yang berbeda.

Terdapat 3 Stasiun pengamatan yang ditetapkan berdasarkan karakteristik fisik habitat yang berbeda, yaitu:

- Stasiun I, terletak pada posisi $3^{\circ} 125,46^{\prime \prime}$ LS dan 128 $04^{\prime} 26,38^{\prime \prime}$ BT, didominasi substrat pasir halus bercampur lumpur dan terletak dekat pemukiman penduduk. Jarak tumbuh lamun pertama \pm 10 meter dari garis pantai. Panjang pantai yang masih ditumbuhi vegetasi lamun $300 \mathrm{~m}$ dan lebar $240 \mathrm{~m}$.

- Stasiun II, terletak pada posisi $3^{\circ} 1^{\prime} 18,70^{\prime \prime}$ LS dan $128^{\circ} 04^{\prime} 27,27^{\prime \prime}$ BT, didominasi substrat pasir kasar dan terletak dekat pemukiman penduduk. Jarak tumbuh lamun pertama \pm 12 $\mathrm{m}$ dari garis pantai, dengan panjang pantai yang masih ditumbuhi vegetasi lamun $250 \mathrm{~m}$ dan lebar $240 \mathrm{~m}$.
- Stasiun III, terletak pada posisi $3^{\circ} 11^{\prime} 18,72^{\prime \prime} \mathrm{LS}$ dan $128^{\circ} 04^{\prime} 34,76^{\prime \prime}$ BT didominasi substrat pasir bercampur patahan karang dan berbatu serta jauh dari pemukiman penduduk. Jarak tumbuh lamun pertama $\pm 14 \mathrm{~m}$ dari garis pantai, dengan panjang garis pantai yang masih ditumbuhi vegetasi lamun $150 \mathrm{~m}$ dan lebar $240 \mathrm{~m}$.

\subsection{Metode Sampling}

Pengamatan kerapatan lamun menggunakan metode sistematik sampling (Setyobudiandy et al., 2009) dengan bantuan transek dan kuadran (1x1 m) yang diletakkan tegak lurus garis pantai pada saat surut terendah.

Contoh setiap jenis lamun diambil untuk diidentifikasi jenisnya. Pengambilan substrat dasar perairan pada setiap stasiun pengamatan secara acak pada awal, pertengahan, dan akhir kuadran dengan menggunakan pipa paralon berdiameter 1.5 inci. Pengukuran parameter kualitas air meliputi: suhu, salinitas, kecerahan, kedalaman dan kecepatan arus.

\subsection{Analisis Data}

Analisa data dilakukan untuk mengetahui beberapa parameter ekologi vegetasi lamun, meliputi: komposisi jenis, kerapatan, dan struktur komunitas (keanekaragaman, keseragaman, dominansi).

\subsubsection{Komposisi Jenis Lamun}

Komposisi jenis lamun diketahui dengan membandingkan jumlah individu masing-masing jenis dengan total individu seluruh jenis dimodifikasi dari Fachrul (2007):

$$
\mathrm{Kj}=\frac{\mathrm{ni}}{\mathrm{N}} \times 100 \%
$$

Dimana:

$$
\begin{aligned}
\mathrm{Kj} & =\text { Komposisi jenis vegetasi lamun }(\%) \\
\mathrm{ni} & =\begin{array}{l}
\text { Jumlah individu setiap jenis vegetasi } \\
\text { lamun. }
\end{array} \\
\mathrm{N} & =\begin{array}{l}
\text { Jumlah individu seluruh jenis vegetasi } \\
\text { lamun. }
\end{array}
\end{aligned}
$$

\subsubsection{Kerapatan Jenis Lamun}

Kerapatan jenis lamun adalah jumlah individu (tegakan) per satuan luas. Kerapatan masing-masing jenis dihitung dengan menggunakan rumus Odum (1971) sebagai berikut:

$$
D_{i}=\frac{N i}{A}
$$

Di mana :

$\mathrm{Di}=$ Kerapatan $/$ kepadatan jenis $\left(\mathrm{ind} / \mathrm{m}^{2}\right)$

$\mathrm{Ni}=$ Jumlah total individu spesies

$\mathrm{A}=$ Luas daerah yang disampling 


\subsubsection{Struktur Komunitas Lamun}

Nilai indeks Dominansi memberikan gambaran tentang dominansi organisme dalam suatu komunitas ekologi. dengan formula Margalef (1958) dalam odum (1983):

$$
\mathrm{C}=\sum \frac{\mathrm{ni}(\mathrm{ni}-1)}{\mathrm{N}(\mathrm{N}-1)}
$$

Dimana :

$$
\begin{aligned}
& \mathrm{C}=\text { Indeks Dominansi Simpson, } \\
& \mathrm{N}=\text { Jumlah individu seluruh spesies, } \\
& \mathrm{ni}=\text { Jumlah individu dari jenis ke-i. }
\end{aligned}
$$

Indeks keanekaragaman adalah nilai yang dapat menunjukkan keseimbangan keanekaragaman dalam suatu pembagian jumlah individu tiap jenis. Nilai indeks keanekaragaman Shannon (H') menurut Shannon and Wiener (1949) dalam Odum (1983):

$$
\mathrm{H}^{\prime}=-\Sigma \mathrm{Pi} \ln (\mathrm{Pi})
$$

Dimana :

$$
\begin{aligned}
& \mathrm{H}^{\prime}=\text { Indeks Keanekaragaman, } \\
& \mathrm{Pi}=\text { Proporsi jumlah individu (ni/N). }
\end{aligned}
$$

Indeks keseragaman (E), diketahui dengan menggunakan persamaan menurut Pielou (1966) dalam Odum (1983) :

$$
\begin{aligned}
& \mathrm{E}=\frac{\mathrm{H}}{\ln \mathrm{S}} \\
& \text { Dimana : } \\
& \mathrm{E} \quad=\text { Indeks Keseragaman Evennes- } \\
& \mathrm{H}^{\prime}=\text { Simpson, } \\
& \mathrm{S} \quad=\text { Indeeks Keanekaragaman } \\
&
\end{aligned}
$$

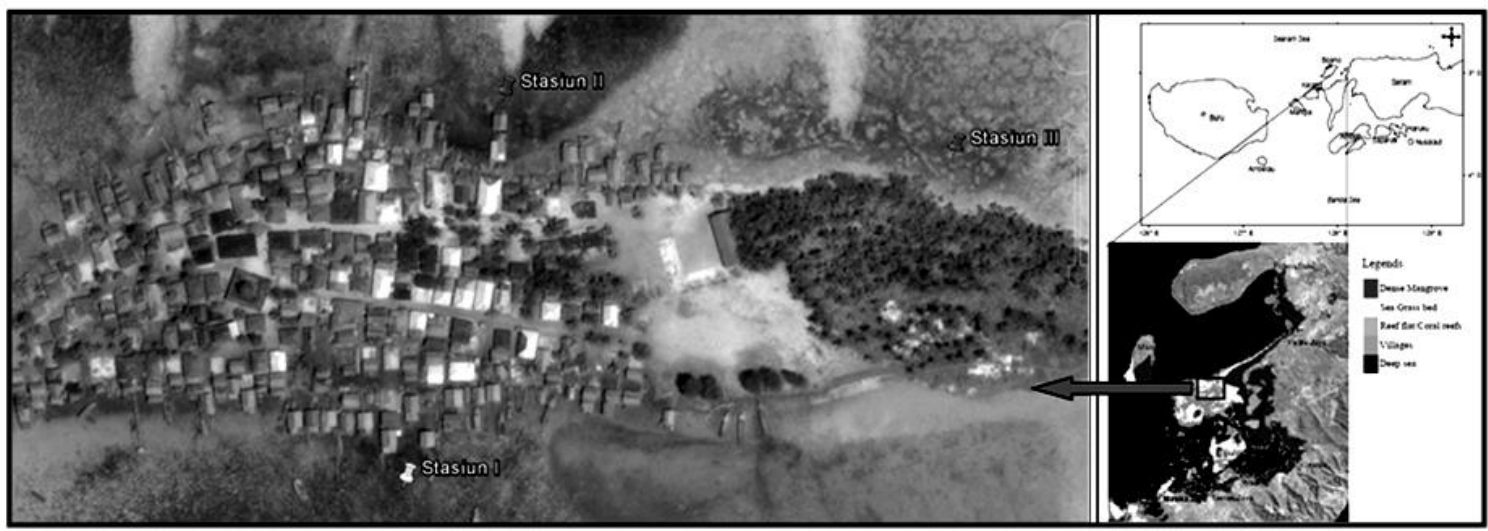

Gambar 1. Peta Perairan Pulau Osi Teluk Kotania Dengan Tiga Stasiun Pengamatan

Tabel 1. Kriteria Indeks Keanekaragaman, Keseragaman dan Dominansi

\begin{tabular}{lcc}
\hline Indeks & Kisaran & Kategori \\
\hline Dominansi $(\mathrm{C})$ & $0,00<\mathrm{C} \leq 0,50$ & Rendah \\
& $0,50<\mathrm{C} \leq 0,75$ & Sedang \\
& $0,75<\mathrm{C} \leq 1,00$ & Tinggi \\
\hline Keanekaragaman $\left(\mathrm{H}^{\prime}\right)$ & $\mathrm{H}^{\prime}<1$ & Rendah \\
& $1<\mathrm{H}^{\prime}<3$ & Sedang \\
& $\mathrm{H}^{\prime}>3,0$ & Tinggi \\
\hline Keseragaman $(\mathrm{E})$ & $0,00<\mathrm{E} \leq 0,50$ & Komunitas dalam kondisi Tertekan \\
& $0,50<\mathrm{E} \leq 0,75$ & Komunitas dalam kondisi Labil \\
& $0,75<\mathrm{E} \leq 1,00$ & Komunitas dalam kondisi Stabil \\
\hline
\end{tabular}

Sumber : Setyobudiandi et al, 2009

III. HASIL DAN PEMBAHASAN

\subsection{Deskripsi Lokasi Penelitian}

Pulau Osi terletak dalam kawasan perairan Teluk Kotania, sebelah Timur berbatasan dengan Daratan pulau Seram, sebelah Barat berbatasan dengan pulau Marsegu, Selatan berbatasan dengan pulau Burung dan sebelah Utara berbatasan dengan perairan Teluk Kotania.
Perairan pulau Osi memiliki topografi pantai yang landai dengan areal pasang surut yang cukup luas. Tipe pasang surut yang terjadi pada perairan pulau Osi adalah semi diurnal atau pasang surut yang terjadi dua kali selama sehari. 


\subsection{Parameter Lingkungan Perairan}

Parameter lingkungan perairan meliputi suhu, salinitas, kecepatan arus, kecerahan dan kedalaman yang diduga mempengaruhi pertumbuhan vegetasi lamun pada tiap stasiun penelitian seperti terlihat pada Tabel 2.

\subsubsection{Suhu}

Hasil pengukuran parameter lingkungan perairan Pulau Osi didapatkan nilai suhu perairan yang sama yaitu $28^{\circ} \mathrm{C}$ nilai ini cukup rendah karena penelitian ini dilakukan pada musim hujan, bila dibandingkan dengan hasil penelitian Hadijah (2000) Di Pearairan Pulau Kodingareng Kota Makassar, menemukan kisaran suhu yang lebih tinggi dengan kisaran $29-30{ }^{\circ} \mathrm{C}$ karna penelitian di lakukan pada musim kemarau, sedangkan Syari (2005, mendapatkan kisaran suhu yang berbeda antara $29.5-31{ }^{\circ} \mathrm{C}$ pada ekosistem padang lamun di perairan pulau Lepar Kepulauan Bangka-Belitung.

Meskipun demikian nilai suhu perairan yang didapatkan di perairan pulau Osi ini masih ideal untuk pertumbuhan lamun. Dimana menurut Ziemen (1975) dalam Supriharyono (2007), lamun di perairan tropis tumbuh dengan baik pada kisaran suhu $20-30^{\circ} \mathrm{C}$ dengan kisaran suhu optimum $28-30^{\circ} \mathrm{C}$.

\subsubsection{Salinitas}

Salinitas yang didapatkan pada perairan pulau Osi yaitu $32 \%$. Hasil ini kurang lebih sama dengan penelitian Hadijah (2000) Di Perairan Pulau Kodingareng Kota Makassar dengan kisaran salinitas antara 31-32 \%o. Sementara Syari (2005) mendapatkan kisaran salinitas perairan pulau Lepar Kepulauan Bangka-Belitung lebih tinggi dengan kisaran 28$34 \%$.

Meskipun demikian kisaran nilai salinitas perairan yang didapatkan pada ekosistem padang lamun perairan pulau Osi ini masih merupakan kisaran yang layak bagi pertumbuhan lamun, dimana menurut Ziemen (1975) dalam Supriharyono (2007) secara umum salinitas yang optimum untuk pertumbuhan lamun berkisar antara $25-35 \%$.

\subsubsection{Kecepatan Arus}

Kecepatan arus yang terukur pada perairan pulau Osi tergolong rendah yang berkisar antara $0,4-0,6 \mathrm{~m} / \mathrm{dtk}$, karena secara geografis pulau Osi terletak pada teluk Kotania dan diapit beberapa pulau lainnya sehingga cukup terlindungi. Meskipun demikian kecepatan arus yang didapartkan ini masih lebih tinggi jika dibandingkan dengan nilai kecepatan arus yang didapat oleh Syari (2005) pada ekosistem padang lamun pulau Lepar Kepulauan Bangka-Belitung dengan kisaran hanya $0,01-0,03 \mathrm{~m} / \mathrm{dtk}$ karena sama-sama merupakan daerah yang terlindung dan diapit oleh pulau-pulau disekitarnya.

Meskipun demikian nilai kecepatan arus yang didapatkan pada ekosistem padang lamun perairan pulau Osi masih layak bagi pertumbuhan vegetasi lamun, dimana menurut Berwick (1983) dalam Hadijah (2002), kecepatan arus untuk kehidupan lamun 0,5 m/det.

\subsubsection{Kecerahan}

Kecerahan pada perairan pulau Osi sangat tinggi (100\%), disebabkan kondisi perairan pada saat pengmatan cukup tenang dan jernih dan tidak ada aktivitas masyarakat yang dapat membawa material lumpur, sehingga penetrasi cahaya maksimal sampai pada dasar perairan dengan kedalaman perairan berkisar antara 1,802,40 . Hasil yang didapatkan ini berbeda dengan hasil temuan Syari (2005) pada ekosistem padang lamun pulau Lepar Kepulauan Bangka-Belitung dengan nilai kecerahan $86-90 \%$ dikarenakan pada lokasi tersebut dipengaruhi oleh masa air laut di Perairan Sadai Pulau Bangka yang keruh akibat aktivitas penambangan timah inkonvensional di daerah pantai dan darat.

Pada perairan alami, kecerahan sanagat penting karna erat kaitanya dengan proses fotosintesis. Menurut Berwick (1983) dalam Erina (2006), distrubusi dan kelimpahan lamun juga dibatasi oleh ketersediaan cahaya hal ini dapat dilihat dari sebaran yang terbatas pada daerah yang masih dapat ditembus cahaya matahari. Sementara itu, menurut Dahuri (2003), bahwa tingkat kecerahan untuk pertumbuhan lamun adalah berkisar antara $1-90 \mathrm{~m}$.

\subsubsection{Kedalaman}

Hasil pengukuran kedalaman pada perairan pulau Osi saat pasang berkisar antara 1,80 - 2,40 meter. Pada stasiun I mempunyai kedalaman 2,40 meter, sedangkan pada stasiun II dan III mempunyai kedalaman yang sama yaitu 1,80 meter. Hasil penelitian yang didapatkan ini masih lebih tinggi dibandingkan penelitian Nainggolan (2011), yang mendapatkan kedalaman perairan pada beberapa stasiun pengmatan pada eksosistem padang lamun Teluk Bakau Kepulauan Riau dengan kisaran 1,16 - 1,72

Meskipun demikian kisaran kedalaman yang diapatkan ini masih ideal bagi pertumbuhan lamun, dimana menurut Zottolu (1983) dalam Mandang (1997), bahwa kedalaman perairan untuk pertumbuham lamun berkisar anatar $0,5-100$. 


\subsubsection{Substrat Dasar Perairan}

Hasil pengukuran sedimen pada lokasi penelitian dapat dilihat pada Tabel 3

Dari Tabel 3 di atas terlihat secara keseluruhan tipe substrat berbeda pada masingmasing stasiun pengamatan, pada stasiun I substrat sedimen yang dominan yaitu pasir halus dan endapan lumpur, ini dikarenakan letak lokasi relatif terlindungi karena diapit oleh pulau disekitarnya, sedangkan pada stasiun II dan III substrat sedimen yang dominan adalah pasir kasar dan patahan karang, ini dikarenakan letak lokasi penelitian yang berhadapan langsung dengan teluk Kotania, sehingga tidak ada yang menghalangi pergerakan gelombang dan arus.

Tabel 2 Parameter Lingkungan Perairan pada setiap Stasiun Pengamatan

\begin{tabular}{clccc}
\hline No & Parameter Lingkungan & Stasiun I & Stasiun II & Stasiun III \\
\hline 1 & Suhu $\left({ }^{\circ} \mathrm{C}\right)$ & 28 & 28 & 28 \\
2 & Salinitas $(\%)$ & 32 & 32 & 32 \\
3 & Kecepatan Arus ( m/det $)$ & 0,4 & 0,4 & 0,6 \\
4 & Kecerahan $(\%)$ & 100 & 100 & 100 \\
5 & Kedalaman ( m) & 2,40 & 1,80 & 1,80 \\
\hline
\end{tabular}

Tabel 3. Tipe Substrat dasar perairan pada setiap stasiun pengamatan

\begin{tabular}{|c|c|c|}
\hline No. & Stasiun I & Tipe Substrat / Sedimen \\
\hline 1. & Awal Transek & Pasir halus dan endapan lumpur \\
\hline 2. & Pertengahan Transek & Pasir halus dan endapan lumpur \\
\hline 3. & Akhir Transek & Pasir halus dan endapan lumpur \\
\hline \multicolumn{3}{|c|}{ Stasiun II } \\
\hline 1. & Awal Transek & Pasir kasar \\
\hline 2. & Pertengahan Transek & Pasir kasar \\
\hline 3. & Akhir Transek & Pasir kasar dan patahan karang \\
\hline \multicolumn{3}{|c|}{ Stasiun III } \\
\hline 1. & Awal Transek & Pasir kasar dan patahan karang \\
\hline 2. & Pertengahan Transek & Pasir kasar, patahan karang, dan berbatu \\
\hline 3. & Akhir Transek & Pasir kasar, patahan karang, dan berbatu \\
\hline
\end{tabular}

\subsection{Jumlah dan Komposisi Jenis Lamun}

Hasil pengamatan jenis lamun (Tabel 4) terdapat 4 jenis lamun. Ke empat spesies lamun tersebut terdiri dari 2 famili yaitu, Hydrocharitaceae meliputi 3 jenis lamun yaitu Enhalus acoroides, Halophila ovalis, dan Thalassia hemprichii. Sedangkan dari famili Potamogenotaceae meliputi 1 jenis lamun yaitu Cymodocea rotundata.

Jumlah jenis lamun yang ditemukan ini tergolong tinggi dan merupakan tipe ekosistem padang lamun multispesifik yang tersusun lebih dari dua jenis vegetasi lamun. Namun jika dibandingkan dengan penelitian Cappenberg (1996) yang menemukan 5 jenis lamun pada perairan pulau Osi yaitu : Enhalus acoroides, Thalassia hemprichii, Halophila ovalis, dan Cymodocea rotundata, dan Halodule uninervis. Fenomena ini menunjukkan terjadi penurunan jumlah jenis lamun di perairan pulau Osi.

Sementara itu berdasarkan komposisi jenis pada Gambar 2, menunjukkan bahwa Thalassia hemprichii merupakan vegetasi lamun dengan komposisi jenis tertinggi, sementara Halophila ovalis ditemukan dengan komposisi jenis terendah pada stasiun II dan III, sedangkan pada stasiun I yang terendah dari jenis Enhalus acoroides.

Berdasarkan persentase komposisi jenis lamun (Gambar 2) untuk seluruh stasiun pengamatan, jenis yang cukup mendominasi yaitu Thalassia hemprichii. Fenomena ini didukung oleh penyataan Brouns dan Heijs (1991), bahwa padang lamun dengan vegetasi campuran umumnya terdiri dari sedikitnya 4 dari 7 jenis yaitu: Cymodocea rotundata, Cymodocea serrulata, Enhalus acoroides, Halodule uninervis, Halophila ovalis, Syringodium isoetifolium dan Thalassia hemprichii, tetapi dalam struktur komunitasnya selalu terasosiasi Enhalus acoroides dan Thalassia hemprichii yang selalu mendominasi.

Dibandingkan hasil penelitian Cappenberg (1996), di perairan pulau Osi pada 2 stasiun pengamatan yang sama khususnya Stasiun I dan 
II dimana ditemukan 5 jenis lamun dengan dominasi tertinggi adalah jenis Thalassia hemprichii dibandingkan jenis lainnya. Fenomena ini menunjukkan adanya perubahan komposisi jenis yang diduga akibat perubahan lingkungan fisik perairan.

\subsection{Kerapatan Jenis lamun}

Berdasarkan Tabel 5 pada stasiun I kerapatan jenis tertinggi yaitu Thalassia hemprichii 36,05 ind $/ \mathrm{m}^{2}$ dan terendah Enhalus acoroides $16,87 \mathrm{ind} / \mathrm{m}^{2}$. Pada stasiun II kerapatan jenis tertinggi Thalassia hemprichii $21,39 \mathrm{ind} / \mathrm{m}^{2}$ dan terendah Halophila ovalis $4,29 \mathrm{ind} / \mathrm{m}^{2}$. Sedangkan pada stasiun III kerapatan jenis tertinggi Thalassia hemprichii sebesar $12 \mathrm{ind} / \mathrm{m}^{2}$ dan terendah Halophila ovalis sebesar 6,42 ind $/ \mathrm{m}^{2}$.

Tabel 4. Jenis lamun yang ditemukan pada perairan pulau Osi - Seram Bagian Barat

\begin{tabular}{|c|c|c|}
\hline Famili & Spesies & Foto / Gambar \\
\hline \multirow{3}{*}{ Hidrocharitaceae } & Enhalus acoroides & \\
\hline & Halophila ovalis & \\
\hline & Thalassia hemprichii & \\
\hline Potamogenotaceae & Cymodocea rotundata & 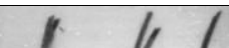 \\
\hline
\end{tabular}

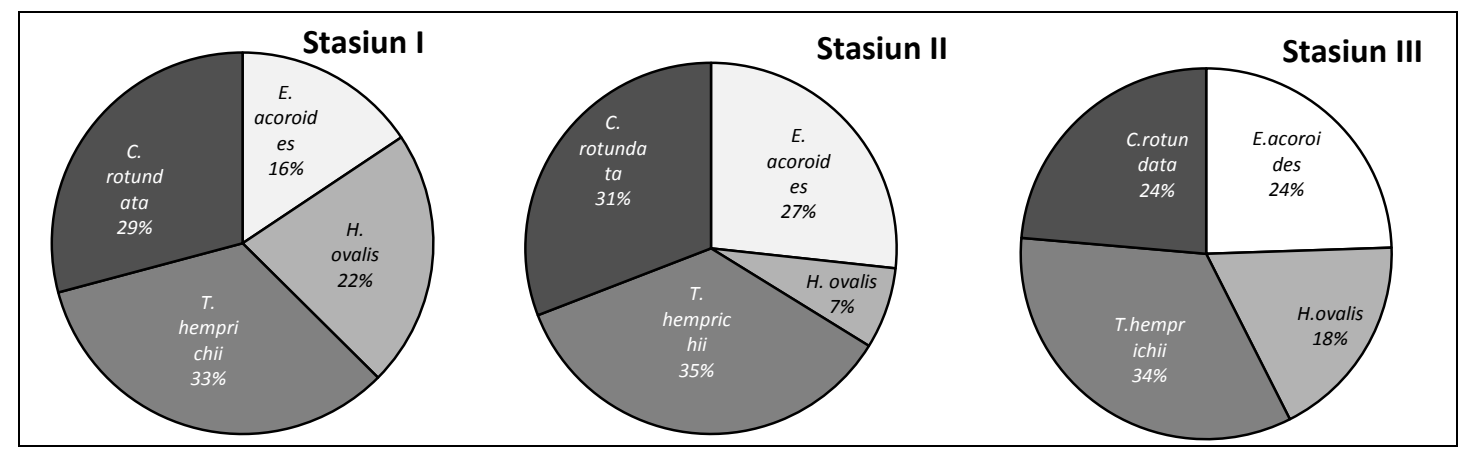

Gambar 2. Komposisi jenis Lamun di perairan Pulau Osi di setiap Stasiun Pengamatan. 
Tabel 5. Kerapatan Jenis vegetasi Lamun (ind $/ \mathrm{m}^{2}$ ) pada lokasi penelitian

\begin{tabular}{|c|c|c|c|c|}
\hline \multirow{2}{*}{ No } & \multirow{2}{*}{ Jenis Lamun } & \multicolumn{3}{|c|}{ Kerapatan Lamun (D) } \\
\hline & & Stasiun I & Stasiun II & Stasiun III \\
\hline 1 & Enhalus acoroides & 16,87 & 16,18 & 8,68 \\
\hline 2 & Halophila ovalis & 23,53 & 4,29 & 6,42 \\
\hline 3 & Thalassia hemprichii & 36,05 & 21,39 & 12,00 \\
\hline 4 & Cymodocea rotundata & 31,45 & 18,69 & 8,38 \\
\hline
\end{tabular}

Sumber : Analisa Data Primer 2012

Tingginya kerapatan jenis Thalassia hemprichii dari jenis yang lain merupakan hal yang alamiah dan sesuai dengan habitatnya, dimana menurut Kiswara (1992), Thalassia hemprichii tumbuh dengan baik pada dasar lumpur sampai pasir dan patahan karang.

Sementara itu tingginya kerapatan jenis lamun pada stasiun I berkaitan diduga berkaitan erat dengan tipe substrat dasar perairan tempat tumbuhnya yang berupa pasir halus bercampur lumpur. Dimana menurut Erftemeijer et al (1994), lamun yang tumbuh pada substrat berlumpur mempunyai konsentrasi ' $\mathrm{N}$ ' dan ' $\mathrm{P}$ ' jaringan lebih tinggi daripada yang ditemukan pada substrat pasir dengan konsentrasi bahan organik rendah.

\subsection{Struktur Komunitas Lamun}

Berdasarkan Tabel 6, terlihat bahwa struktur komunitas setiap stasiun pengmatan cukup bervariasi, dimana dominansi tertinggi ditemukan pada stasiun II dengan substrat dasar perairan berupa pasir kasar dengan nilai 0.30 , sementara dominansi terendah ditemukan pada stasiun III dengan substrat pasir kasar bercampur patahan karang dengan nilai 0.26. Sebaliknya nilai indeks keanekaragaman tertinggi ditemukan pada stasiun III sebesar 0.98 dan terendah ditemukan pada stasiun II sebesar 0.92 . Meskipun demikian nilai indeks dominansi masih masuk dalam kategori rendah, sementara nilai indeks keanekaragaman masuk kategori sedang, dan indeks keseragaman masuk kategori stabil.

Menurut Brower et al, (1990), keanekaragaman jenis adalah suatu ekspresi dari struktur komunitas, dimana suatu komunitas dikatakan memiliki keanekaragaman jenis tinggi, jika proporsi antar jenis secara keseluruhan sama banyak. Sehingga jika ada beberapa jenis dalam komunitas yang memiliki dominansi yang besar maka keanekaragaman dan keseragamannya rendah. Fenomena ini membuktikan bahwa secara ekologi tidak ada spesies yang mendominasi dalam struktur komunitas lamun pada perairan pulau Osi, sehingga kestabilannya terjaga.

Tabel 6. Struktur Komunitas Lamun Perairan Pulau Osi

\begin{tabular}{lcccc}
\hline \multirow{2}{*}{ Struktur Komunitas } & \multicolumn{3}{c}{ Stasiun Pengamatan } & \multirow{2}{*}{ Kategori } \\
\cline { 2 - 4 } & I & II & III & \\
\hline Dominansi (C) & 0.27 & 0.3 & 0.26 & Rendah \\
Keanekaragaman ('H) & 1.35 & 1.27 & 1.36 & Sedang \\
Keseragaman (E) & 0.97 & 0.92 & 0.98 & Stabil \\
\hline Sumber: Analisa Data Primer 2012 & & & &
\end{tabular}

\section{PENUTUP}

\subsection{Kesimpulan}

- Ditemukan 4 jenis vegetasi lamun yang termasuk ke dalam 2 famili, yaitu: (1) Enhalus acoroides, Thalassia hemprichii dan Halophila ovalis yang termasuk dalam famili Hydrocharitaceae, sementara yang termasuk famili Potamogenotaceae yaitu : Cymodocea rotundata, dengan Komposisi jenis vegetasi lamun tertinggi adalah Thalassia hemprichii dan terendah adalah Halophila ovalis.

- Nilai struktur komunitas meliputi indeks dominansi masuk kategori rendah, indeks keanekaragaman masuk kategori sedang, dan indeks keseragaman masuk kategori stabil, yang menunjukkan secara ekologi tidak ada 
spesies yang sangat mendominasi sehingga kestabilan komunitas terjaga.

- Karakteristik fisik sedimen menentukan distribusi spasial, keragaman dan kerapatan jenis vegetasi lamun di perairan pulau Osi, dimana subsrat pasir halus bercampur lumpur memiliki kerapatan vegetasi lamun yang tinggi dibandingkan dengan dominasi fraksi pasir kasar bercampur patahan karang dan berbatu.

\subsection{Saran}

Diperlukan upaya konservasi ekosistem padang lamun di perairan pulau Osi, dengan mengurangi aktivitas masyarakat yang dapat menyebabkan tingkat kekeruhan yang tinggi sebagai penyebab menurunnya produktivitas primer dan mengancam penurunan dan kehilangan jenis vegetasi lamun secara khusus dan mereduksi luasan ekosistem padang lamun secara umum.

\section{DAFTAR PUSTAKA}

Brouns, J.J.W.M. and F.A.M.I. Heijs. 1991. Seagrass ecosystem in the tropical West Pacific, in Mathieson and Nienhuis (eds). Intertidal and Litoral Ecosystem. Serie Ecosystem of the World. Elsevier Science Pub. New York. No. (24):371-390.

Brower, J.E., J.H. Zar, and C.N. Von Ende. 1990. Field and Laboratory Methods for General Ecology. Wim. C. Brown Co. Pub.Dubuque. Iowa. 237 pp.

Cappenberg, H.A.W. 1996. Komunitas Moluska di Teluk Kotania Seram Barat. Perairan Maluku dan Sekitarnya. Vol. $11: 19-33$.

Dahuri, R. 2003. Keanekaragaman Hayati Laut Aset Pembangunan Berkelanjutan Indonesia. Penerbit Gramedia Pustaka Utama. Jakarta. 412 pp.

Erina Y. 2006. Keterkaitan Antara Komposisi Perifiton Pada Lamun Enhalus acoroiides (Linn.F) Reylo Dengan Tipe Substrat Lumpur Dan Pasir Di Teluk Banten Tesis. Bogor: Program Pascasarjana, Institute Pertanian Bogor.

Erftemijer,P.LA., Stapel,M.J.E. Smakens and W.E. Drosseart. 1994. The Limited Effect of im Phosphorus and Nitrogen Additions to Seagrass Beds in Carbonate and Terrigenous Sedimets in South Sulawesi. Indonesia. J.Exp. mar. Biol. Ecol. 182:123-140.

Fachrul, 2007. Metode Sampling Bioekologi. Penerbit. Bumi Askara. Jakarta. 198 pp.

Hadijah, 2000. Sebaran Spasial Komunitas Gastropoda dan Asosiasinya dengan Lamu di Perairan Pulau Kodingareng Kotamadya Makasar. Tesis. Fakultas Pasca Sarjana IPB. Bogor. 122 pp.

Kordi, M.G.H. 2011. Ekosistem Lamun (seagrass). Fungsi, Potensi, Pengelolaan. Rineka Cipta. Jakarta. $191 \mathrm{pp}$.

Mandang, R. 1997. Komonitas Gastropoda Di Perairan Bunaken Sulawesi Utara. Skripsi. Fakultas Perikanan Dan Ilmu Kelautan. Universitas Sam Ratulangi. Manado.

Nainggolan, P. 2011. Distribusi Spasial dan pengelolaan Lamun (Seagrass) di Teluk Bakau Kepulauan Riau. Skripsi. Fakultas Perikanan dan Ilmu Kelauatan-IPB. Bogor. 95 pp.

Nontji,A. 2007. Laut Nusantara. Cetakan Kelima. Djambatan. Jakarta. 372 pp.

Nybakken, J.W. 1992. Biologi Laut; Suatu Pendekatan Ekologis. Gramedia Pusataka Utama. Jakarta. $443 \mathrm{pp}$.

Odum, E.P. 1970. Fundamental of Ecology. W.B. Sounders. Philadel-phia. 574 pp.

Odum, E.P. 1983. Basic Ecology. Saunders College Publishing, New York. 612 pp.

Setyobudiandi, I. Sulistiono., Kusmana., S.Hariyadi.,A.Damar.,A.Sembiring., dan Bahtiar.2009. Sampling dan Analisis Data perikanan dan Kelautan, terapan metode Pengambilan contoh di wilayah pesisir dan laut. 312 pp.

Supriharyono, 2007. Konservasi Sumberdaya Hayati di Wikayah Pesisir Tropis. Pustaka Pelajar. Yogyakarta. $470 \mathrm{pp}$.

Syari, I.A. 2005. Asosiasi Gastopoda di Ekosistem Padang Lamun Pulau Lepar Provinsi Kepulauan Bangka Belitung. Skiripsi. Fakultas Perikanan dan Ilmu Kelautan - IPB. Bogor. 68 pp. 